\title{
Long-term Survival After Aortic Valve Replacement with the Mitroflow Bioprosthesis: a Comparative Study
}

\author{
Alexander Manché ${ }^{1}$, Liberato Camilleri ${ }^{2}$ \\ 1. Cardiothoracic Surgery Department, Mater Dei Hospital, Malta \\ 2. Department of Statistics and Operations Research, Faculty of Science, University of Malta
}

\section{Corresponding author:}

Alexander Manché

Cardiothoracic Surgery Department,

Mater Dei Hospital, Malta

E mail: manchea@maltanet.net

\begin{abstract}
\section{Background}

Recent case reports of early structural degeneration of the Mitroflow valve have cast doubts on the suitability of this bioprosthesis, particularly in the smaller sizes, and in younger patients. We studied long-term patient survival, in a comparative study, as a marker of success after aortic valve replacement.

Methods

Long-term survival in 142 consecutive patients implanted with the Mitroflow valve was compared, using the Kaplan-Meier method, with a control group of 149 patients receiving different bioprostheses. Ninety two percent of patients were over 70 years and the Mitroflow was used preferentially in smaller sizes.

\section{Results}

Long-term survival in patients who received a Mitroflow valve was equivalent to controls. Four documented cases of premature structural valve degeneration (3 Mitroflow, 1 Perimount) required a second intervention.

\section{Conclusions}

The Mitroflow compared favorably with other valves in our practice. Although a few patients required further treatment this had no significant adverse impact on overall survival.
\end{abstract}

Keywords: Mitroflow aortic bioprosthesis; premature structural valve degeneration; long-term survival

Citation: $\quad$ Manché A, Camilleri L . Long-term Survival After Aortic Valve Replacement with the Mitroflow Bioprosthesis: a Comparative Study. International Cardiovascular Forum Journal. 2019;16:28-31. DOI: 10.17987/icfj.v16i0.533

\section{Introduction}

A rising life expectancy of up to 80 for males and 84 for females [1] in our local population has favored an increased use of biological prostheses in the surgical treatment of aortic valve disease. We started implanting the Mitroflow Model 12A valve in 2001 and used it preferentially in the smaller-sized annulus due to its excellent haemodynamic performance [2] and ease of insertion. In 2006 we switched to the Mitroflow LX in line with the manufacturer's recommendations.

Structural valve degeneration (SVD) has been reported with both the $12 \mathrm{~A}$ and $\mathrm{LX}$ models and is thought to relate to the lack of anticalcification treatment, $[3,4,5]$ a feature present in other early valve models.[6] This complication has been reported with increasing frequency in patients under 70 and in the size 19 valve, in severe prosthesis-patient mismatch $[7,8,9]$ but also occasionally in larger sizes. $[10,11]$ In spite of these clinical situations, long-term outcomes in large series have been favorable.[8,9,12,13]

Premature SVD may be under-reported because it is usually recognized when re-intervention is indicated.[14] Retrospective series of patients receiving the Mitroflow valve and case reports with this and other valves [15] have highlighted this clinical problem. Comparative studies are, however, sparse. Many elderly patients are not candidates for repeat surgery or valve-in-valve transcatheter implantation because of co-morbidities or technical considerations and so the real impact of SVD may be reflected in premature death. We have therefore sought to compare the long-term survival of our Mitroflow patients with matched controls receiving other valves in order to better understand the clinical relevance of SVD. 


\section{Methods \\ Patients and clinical protocol}

All patients undergoing surgical aortic valve replacement in a single-surgeon practice between April 1st 1995 and December 31st 2017 were included in this study. The threshold for bioprosthetic valve implantation was set at 70 years and $92 \%$ of the patients achieved this target.

During the first 6 years (1995-2001) the Carpentier Edwards valve was the sole bioprosthesis used. From 2001 onwards the Mitroflow valve was introduced and preferentially selected in the small annuli. The choice of valves evolved with time in line with newer models and international trends. Valves implanted included LivaNova Mitroflow (models 12A and LX) 142, Carpentier Edwards porcine 62, Carpentier Edwards Perimount 39, LivaNova Perceval 23, Toronto SPV 10, Carpentier Edwards Perimount Magna 9, Carpentier Edwards Perimount Magna Ease 4 and Intuity Elite 2.

All patients underwent surgery under normothermic cardiopulmonary bypass and myocardial protection was with antegrade cold blood cardioplegia. Concomitant coronary bypass surgery was performed in the standard fashion and the graft of first choice was the internal thoracic artery. The valves were washed rinsed prior to implantation according to the manufacturer's instructions and patients were discharged on aspirin alone unless contra-indicated. Operative technique was consistent, apart from the recent introduction of ministernotomy approach for isolated aortic valve replacement. Severe prosthesis-patient mismatch was defined as an indexed effective orifice area (iEOA) of $0.65 \mathrm{~cm}^{2} / \mathrm{m}^{2}$ or less (Pibarot $\left.{ }^{16}\right)$. The Mitroflow cohort was compared to the cohort of all the other biological valves.

\section{Follow-up}

All patients were followed up at our institution and underwent regular echocardiograms, which were performed with increasing frequency when the clinical indication arose. Structural valve degeneration was deemed to be present when significant aortic stenosis ( $>40 \mathrm{mmHg}$ mean gradient) or regurgitation occurred by echocardiographic assessment. The date of death was obtained from the National Statistics Office. The primary endpoint of the study was post-operative survival duration .

\section{Statistical analysis}

Means and standard deviations were used to measure central tendency and dispersion for continuous variables and frequency tables and crosstabs were used to describe categorical variables. Several statistical techniques were used to carry out statistical inference. The Chi square test was used to compare proportions between two groups, while the Students t-test was used to compare means of continuous variables. The Log Rank test was used to compare Kaplan-Meier survival curves. A p value less than the 0.05 level of significance was taken to indicate statistical significance.

\section{Results}

Table 1. Summarises summarizes the baseline, operative and post-operative data.
Table 1. Data for Mitroflow versus other valve, expressed as percentages or mean $\pm S D$

\begin{tabular}{|c|c|c|c|c|}
\hline parameter & Mitroflow & $\begin{array}{l}\text { other } \\
\text { valves }\end{array}$ & $\begin{array}{l}\text { Chi } \\
\text { square }\end{array}$ & t-test \\
\hline sample size (n) & 142 & 149 & & \\
\hline age & $75.18 \pm 4.29$ & $74.07 \pm 4.29$ & & 0.029 \\
\hline age $<70$ years & $5(3.5 \%)$ & $18(12.1 \%)$ & 0.004 & \\
\hline female & 83 (58.5\%) & $56(37.6 \%)$ & $<0.001$ & \\
\hline Parsonnet & $21.16 \pm 6.03$ & $19.13 \pm 6.45$ & & 0.004 \\
\hline EuroSCORE & $6.85 \pm 1.42$ & $6.57 \pm 1.38$ & & 0.122 \\
\hline $\begin{array}{l}\text { logistic } \\
\text { EuroSCORE }\end{array}$ & $7.28 \pm 3.08$ & $7.47 \pm 4.80$ & & 0.772 \\
\hline height & $1.54 \pm 0.10$ & $1.61 \pm 0.09$ & & $<0.001$ \\
\hline weight & $70.59 \pm 12.5$ & $76.22 \pm 15.49$ & & 0.002 \\
\hline body surface area & $1.69 \pm 0.19$ & $1.80 \pm 0.18$ & & $<0.001$ \\
\hline body mass index & $29.36 \pm 4.83$ & $29.96 \pm 4.77$ & & 0.349 \\
\hline ejection fraction & $69.17 \pm 12.96$ & $68.24 \pm 13.38$ & & 0.714 \\
\hline diabetes & $46 / 130(35.4 \%)$ & $24 / 77$ (31.2\%) & 0.535 & \\
\hline hypertension & $89 / 130$ (68.5\%) & $58 / 77$ (75.3\%) & 0.294 & \\
\hline urgent & $23(16.2 \%)$ & $17(11.3 \%)$ & 0.227 & \\
\hline solitary AVR & 85 (59.9\%) & $106(70.7 \%)$ & 0.052 & \\
\hline $\begin{array}{l}\text { AVR+ } \\
\text { graftsCABG }\end{array}$ & 57 (40.1\%) & 44 (29.3\%) & 0.052 & \\
\hline size 19 & $28(19.7 \%)$ & $4(2.7 \%)$ & $<0.001$ & \\
\hline size 21 & $70(49.3 \%)$ & $35(23.5 \%)$ & $<0.001$ & \\
\hline size 23 & $40(28.2 \%)$ & $56(37.6 \%)$ & 0.096 & \\
\hline size 25 & $4(2.8 \%)$ & $54(36.2 \%)$ & $<0.001$ & \\
\hline $\begin{array}{l}\text { severe mismatch } \\
<0.65 \mathrm{~cm}^{2} / \mathrm{m}^{2}\end{array}$ & $8(5.6 \%)$ & $1(0.7 \%)$ & 0.014 & \\
\hline valve stenosis & $80.0 \%$ & $74.7 \%$ & 0.401 & \\
\hline valve regurgitation & $6.6 \%$ & $9.2 \%$ & 0.384 & \\
\hline $\begin{array}{l}\text { mixed valve } \\
\text { disease }\end{array}$ & $13.4 \%$ & $16.1 \%$ & 0.503 & \\
\hline pseudo-bicuspid & $28.0 \%$ & $36.0 \%$ & 0.234 & \\
\hline $\begin{array}{l}\text { tricuspid } \\
\text { degenerative }\end{array}$ & $62.1 \%$ & $54.7 \%$ & 0.294 & \\
\hline $\begin{array}{l}\text { Isolated AVR cross- } \\
\text { clamp time (min) }\end{array}$ & $54.6 \pm 11.2$ & $51.8 \pm 11.7$ & 0.127 & \\
\hline $\begin{array}{l}\text { AVR+CABG cross } \\
\text {-clamp time (min) }\end{array}$ & $68.7 \pm 11.5$ & $71.2 \pm 12.1$ & 0.397 & \\
\hline $\begin{array}{l}\text { intensive care } \\
\text { stay (days) }\end{array}$ & $1.25 \pm 1.68$ & $1.96 \pm 9.45$ & & 0.376 \\
\hline $\begin{array}{l}\text { step-down ward } \\
\text { stay (days) }\end{array}$ & $4.21 \pm 3.18$ & $4.73 \pm 3.45$ & & 0.180 \\
\hline ventilation (hours) & $13.27 \pm 32.27$ & $17.45 \pm 52.04$ & & 0.435 \\
\hline bleeding (ml) & $496.5 \pm 304.6$ & $499.8 \pm 359.9$ & & 0.937 \\
\hline death & $3(2.1 \%)$ & $5(3.4 \%)$ & 0.522 & \\
\hline dialysis & $13(9.2 \%)$ & $7(4.7 \%)$ & 0.129 & \\
\hline $\begin{array}{l}\text { cerebrovascular } \\
\text { accident }\end{array}$ & $0(0.0 \%)$ & $1(0.7 \%)$ & 0.332 & \\
\hline
\end{tabular}




\section{Demographics}

Ninety-two percent of the patients over 70 years received a bioprosthesis. Younger patients accounted for a significantly higher percentage $(12.1 \%$ versus $3.5 \%, p=0.004)$ with other valves (16 patients: 65-70, 2 patients:60-65) than with Mitroflow valves (5 patients: $65-70)$. There was a trend towards avoiding a bioprosthesis in younger patients with time: 13 patients during the first 7 years versus 10 patients during the last 16 years. Mean age $(p=0.029)$ and female preponderance $(p<0.001)$ were significantly higher in the Mitroflow group. Parsonnet risk was higher in the Mitroflow group $(p=0.004)$, but additive and logistic EuroSCORE were similar. Body surface area was smaller $(p<0.001)$ in the Mitroflow group. The incidence of hypertension and diabetes was similar.

\section{Operative data}

Operative urgency, valve pathology and concomitant coronary surgery were similar. There were significantly more size 19 $(p<0.001)$ and size $21(p<0.001)$ and significantly fewer size 25 $(p<0.001)$ valves implanted in the Mitroflow group. Size 23 valves were equally implanted in the two groups. There were 8 cases of severe prosthesis patient mismatch in the Mitroflow group, all with size 19 (iEOA $\left.0.54-0.65 \mathrm{~cm}^{2} / \mathrm{m}^{2}\right)$ and one case with a Perceval $\mathrm{S}$ valve (iEOA $\left.0.61 \mathrm{~cm}^{2} / \mathrm{m}^{2}\right)(p=0.014)$. Cross-clamp time was similar for the two cohorts.

\section{Structural valve degeneration (SVD)}

A 91 year-old female patient developed clinically relevant stenosis and regurgitation 11 years following implantation of a $23 \mathrm{~mm}$ Mitroflow 12A valve (age at implant 80 years). She was treated successfully with a Corevalve TAVI valve-in-valve procedure and is presently well, aged 95.A 79 year-old male patient developed significant regurgitation 9 years after implantation of a $23 \mathrm{~mm}$ Mitroflow LX valve (age at implant 70 years) and underwent a Corevalve TAVI valve-in-valve procedure. Although he initially improved this patient died within a year.

A 77 year-old female patient developed significant stenosis and regurgitation 7 years after implantation of a $21 \mathrm{~mm}$ Mitroflow LX (age at implant 70 years) for rheumatic valve disease. She was hospitalized with a lobar pneumonia exacerbating congestive heart failure. In view of worsening concomitant mitral stenosis she underwent redo aortic and mitral valve replacement, but died post-operatively of sepsis. The explanted valve exhibited thickened leaflets with reduced mobility, and a single tear adjacent to a strut. Radiography revealed mild diffuse calcification with more prominent calcification localized to two adjacent leaflets close to the affected strut (figure 1). A 79 year-old female patient presented with symptomatic severe aortic stenosis 7 years after implantation of a $21 \mathrm{~mm}$ Perimount valve (age at implant 72 years). She underwent a successful Corevalve TAVI valve-invalve procedure.

\section{Long-term survival}

Maximum follow-up was 22 years (whole population $6.63 \pm 4.81$, Mitroflow $6.10 \pm 3.89$, other valves $7.13 \pm 5.50$ ). Follow-up for the Mitroflow group was shorter than for other valves as it was introduced later into our practice. Long-term survival after Mitroflow implantation was equivalent to controls, with similar Kaplan-Meier curves (figure 2). Log-Rank (Mantel-Cox) test yields a non-significant difference between the two survival curves $(p=0.336)$.
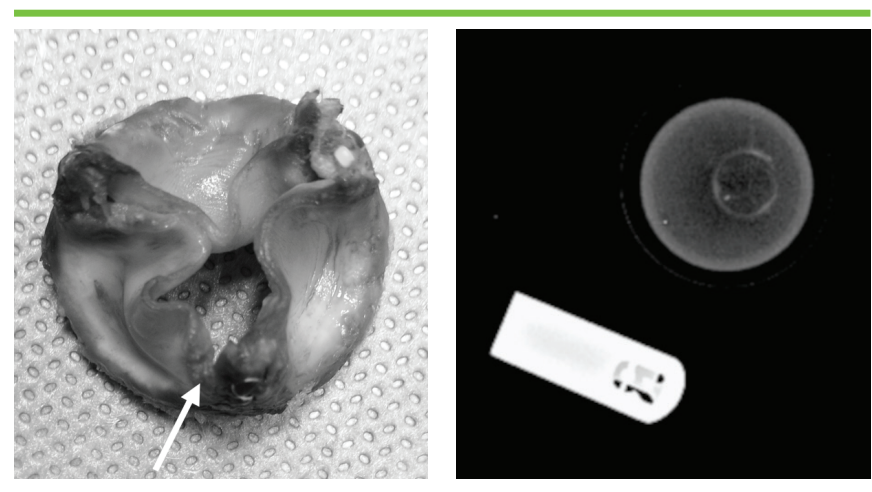

\section{Figure 1}

a) Explanted Mitroflow valve showing thickened leaflets and a tear adjacent to a strut.

b) Radiography reveals speckled calcification adjacent to this strut.

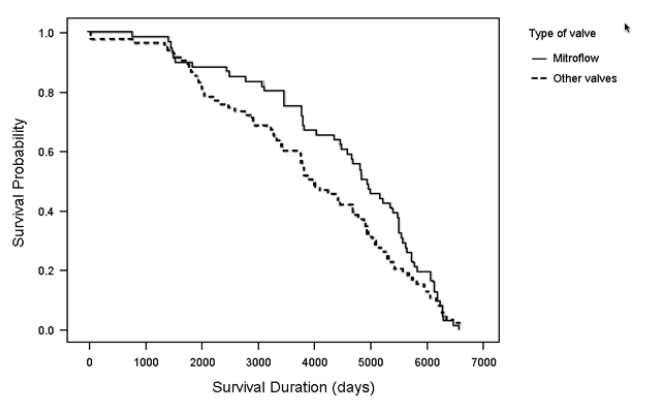

Figure 2

Kaplan-Meier survival curves for patients receiving Mitroflow or other valve

\section{Post-operative data}

There were 8 post-operative deaths $(2.75 \%), 3$ in the Mitroflow group and 5 in the control group $(p=0.522)$. Ventilation time, hospital stay, and complications were similar in the two groups.

\section{Discussion}

A rising life expectancy accounted for a progressively conservative trend in bioprosthetic valve use. The lower incidence of Mitroflow use below the age of 70 years compared with other valves reflects the fact that is was introduced later. The mean age in our study exceeds that in other large series [16] as we aimed to use a bioprosthetic valve in patients over 70 years unless there was a contraindication to anticoagulation or life expectancy deemed to be limited. There is evidence that the use of mechanical valves in patients aged 50-69 results in significantly better long-term survival as well as a reduced rate of intervention.[17] Age and comorbidities at the time of surgery significantly affect longterm survival.[16,18,19] Although up to $30 \%$ of patients are known to exhibit subclinical valve degeneration on echo, with an increase of $>10 \mathrm{~mm} \mathrm{Hg}$ in mean trans-valvular gradient, clinically relevant SVD is infrequent. Less than half of the latter patients undergo a further procedure because of limiting comorbid conditions.[16] Age therefore exerts a larger impact on long-term survival than SVD. In spite of a higher mean age in the Mitroflow patients, long-term survival was similar. The Mitroflow design with excellent haemodynamics even in smaller sizes may have contributed to this outcome, overshadowing the clinically relevant SVD that was present in a few patients. Interestingly the four patients who developed SVD were all over 70 at the time 
of their first surgical intervention and none of the patients with severe prosthesis-patient mismatch developed clinically relevant SVD. The higher proportion of patients under 70 in the control group may have adversely affected the outcome by way of accelerated degeneration known to occur in younger patients. [20] The risk of redo surgery after an aortic bioprosthetic implant is higher in men and increases in patients under 70 years of age. [21] Conversely age at surgery exerts a significant hazard ratio for reduced long-term survival, by a factor of approximately $7 \%$ per annum.[19] The interplay of both these factors is thought to have contributed to the outcome of this study. We believe the excellent long-term results with the Mitroflow valve in this series were achieved when it was implanted in patients over 70 years $(n=137)$ keeping younger patients $(n=5)$ to a minimum.

The Crown PRT, incorporating phospholipid reduction treatment in its manufacturing process has been developed by LivaNova to address early SVD, but retaining the excellent hydrodynamics of its predecessor [22]. Time will tell if this new model can achieve better long-term results than the Mitroflow.

\section{Limitations}

The study is relatively small and confined to a single surgeon practice. Sub-clinical SVD was not investigated and impending clinically relevant SVD may be underestimated. Minor variations in the two groups may have exerted an effect on the outcome.

\section{Conclusion}

Long-term survival after aortic valve replacement with the Mitroflow valve was similar to that in controls. A few Mitroflow patients developed clinically relevant SVD requiring a second intervention. However these sporadic episodes did not affect the excellent overall results in this population. We believe that implanting the Mitroflow valve in patients over 70 whenever possible contributed to this.

\section{Declarations of interest}

The authors declare no conflict of interest.

\section{Acknowledgements}

The authors state that they abide by the authors' responsibilities and ethical publishing guidelines of the International Cardiovascular Forum Journal.[23]

\section{References}

1. National Statistic Office Malta https://www.facebook.com/nsomalta/

2. Gerosa G, Tarzia V, Rizzoli G, Bottio T. Small aortic annulus: the hydrodynamic performances of 5 commercially available tissue valves. J Thorac Cardiovasc Surg. 2006;131:1058-1064 doi:10.1016/jtcvs.2005.12.034

3. Sénage T, Le Tourneau T, Foucher Y, Pattier S, Cueff C, Michel M, et al. Early structural valve degeneration of Mitroflow aortic bioprosthesis: Mode, incidence and impact on outcome in a large cohort of patients. Circulation 2014; CIRCULATIONAHA.114.010400

4. Joshi V, Prosser K, Richens D. Early prosthetic valve degeneration with Mitroflow aortic valves: determination of incidence and risk factors. Interact Cardiovasc Thorac Surg 201419;36-40 doi:10.1093/icvts/ivt372.275

5. Blasco-Lucas A, Rabasa JM, Ortiz D, Miralles A. Early structural valve deterioration of the Mitroflow aortic bioprosthesis: Will the new anticalcification treatment change anything? Rev Esp Cardiol. 2017;70:1152 doi: 10.1016/j.rec.2017.08.008

6. Le Tourneau T, Savoye C, McFadden EP, Grandmougin D, Carton HT, Hennequin JL, Dubar A, Favad G, Warembourg H. Mid-term comparative follow-up after aortic valve replacement with Carpentier-Edwards and Pericarbon pericardial protheses. Circulation. 1999;100(19 suppl):II 11-II 16 doi:10.1161/01.cir.100.2uppl_2.ii-11

7. Diaz R, Hernandez-Vaquero D, Silva J, Pascual I, de la Hera JM, Leon V, Martin M, Barriales V, Colunga S, del Valle R, Moris C. Real structural valve deterioration of the Mitroflow aortic bioprosthesis: Competing risk analysis. Rev Esp Cardiol. 2017;70:1074-1081 doi: 10.1016/j.rec.2017.02.041

8. Piccardo A, Blossier JD, Le Guyader A, Orsel I, Sekkal S, Cornu E, Laskar M. Fate of Mitroflow aortic bioprosthesis: An 18-year experience J Thorac Cardiovasc Surg. 2015;151(3) doi: 10.1016/jtcvs.2015.10.020

9. Mosquera VX, Bouzas-Mosquera A, Velasco-Garcia C, Muniz J, EstévezCid F, Portela-Torron F, Herrera-Norena JM, Cuenca-Castillo JJ. Long-term outcomes and durability of the Mitroflow aortic bioprosthesis. J Card Surg. 2016;31:264-273 doi:10.1111/jocs.12726. Epub 2016 Mar 14

10. Ruvolo G, Pisano C, Balistreri CR, Maresi E, Triolo OF, Argano V, Bassano C, Vacirca SR, Nardi P, Orlandi A. Early structural degeneration of Mitroflow aortic valve: another issue in addition to the mismatch? J Thorac Dis 2018 doi:10.21037/jtd.2018.03.137

11. Fleisher AG, LaFaro RJ, Moggio RA. Immediate structural valve deterioration of the 27-mm Carpentier-Edwards aortic pericardial bioprosthesis. Ann thorac Surg 2004;77:1443-1445 doi:10.1016/s0003-4975(03)01253-0

12. Minami K, Zittermann A, Schulte-Eistrup S, Koertke H, Körfer R. Mitroflow synergy prostheses for aortic valve replacement: 19 years experience with 1,516 patients. Ann Thorac Surg. 2005;80:1699-1705 doi:10.1016/j. athoracsur.2005.04.053

13. Yankah CA, Schubel J, Buz S, Siniawski H, Hetzer R. Seventeen-year clinical results of 1,037 Mitroflow pericardial heart valve prostheses in the aortic position. J Heart Valve Dis. 2005;14:172-179.

14. Webb J, Parkin D, Tendel K, Simitsis P, Roxburgh J, Chambers JB. A comparison of early redo surgery rates in Mosaic porcine and Perimount bovine pericardial valves. Eur J Cardiothorac Surg. 2018 Mar 20. doi:10.1093/ejcys/ezy113

15. Philip R, Kumar TK, Waller BR, McCoy M, Knott-Craig CJ. Near catastrophic accelerated structural degeneration of the Perimount Magna pericardia bioprosthesis in children. Ann thorac Surg 2016;102:308-311 doi:10.1016/j. athoracsur.2015.09.088

16. Rodriguez-Gabella, Voisine P, Dagenais F, Mohammadi S, Perron J, Dumont E, Puri R, Asmarats L, Coté M, Bergeron S, Pibarot P, Rodés-Cabau J. Long-term outcomes following surgical aortic bioprosthesis implantation. $J$ Am Coll Cardiol 2018(71) doi: 10.1016/jacc.2018.01.059

17. Glaser N, Jackson V, Holzmann MJ, Franco-Cereceda A, Sartipy V. Aortic valve replacement with mechanical vs. biological prostheses in patients aged 50-69 years. Eur Heart J. 2016;37:2658-2667 doi:10.1093/eurheart/ ehv580

18. Manché A, Camilleri L, Gauci D. Does aortic valve replacement restore normal life expectancy? A twenty-year relative survival study. Int Cardiovasc Forum J 2016(6) doi: 10.17987/icfj.v610.138

19. Manche A, Casha A, Camilleri L. Long-term survival following aortic valve replacement: the influence of age, prosthesis-patient mismatch and indexed effective orifice area. Int Cardiovasc Forum J 2017(11) doi:10.17987/icfj. v11io.432

20. Banbury MK, Cosgrove DM, White JA, Okies JA. Age and valve size effect on the long-term durability of the Carpentier-Edwards aortic pericardial bioprosthesis. Ann Thorac Surg. 2001;72:753-757 doi:10.1016/S00034975(01)02992-7

21. Weerasinghe A, Edwards M-B, Taylor KM. First redo heart valve replacment. A 10-year analysis. Circulation 1999;99:655-658 doi:10.1161/01. CIR.99.5.655

22. Von Knobelsdorff F, Dieringer MA, Greiser A, Schulz-Menger J. In vitro assessment of heart valve bioprostheses by cardiovascular magnetic resonance: Four-dimensional mapping of flow patterns and orifice planimetry. Eur J Cardiothorac Surg 2011;40:736-742 doi:10.1016/j. ejcts.2010.12.040

23. Shewan LG, Coats AJS, Henein MY. Authors' Responsibilities and Ethical Publishing. International Cardiovascular Forum Journal 2018;13:3-4, DOI: 10.17987/icfj.v13i0.525 